\title{
Consensus on the treatment of hidradenitis suppurativa - Brazilian Society of Dermatology*
}

\author{
Renata Ferreira Magalhães ${ }^{1}$, Maria Cecília Rivitti-Machado², Gleison Vieira Duarte ${ }^{3}$, Roberto Souto ${ }^{4}$ \\ Daniel Holthausen Nunes ${ }^{5}$, Mario Chaves ${ }^{4}$, Sérgio Henrique Hirata ${ }^{6}$, Andrea Machado Coelho Ramos ${ }^{7}$
}

DOI: http:/ /dx.doi.org/10.1590/abd1806-4841.20198607

\begin{abstract}
Hidradenitis suppurativa is a chronic immune mediated disease of universal distribution that causes great damage to the quality of life of the affected individual, whose prevalence is estimated at $0.41 \%$ in the Brazilian population. The objective of this work was update on physiopathogenesis, diagnosis and classification of hidradenitis suppurativa and to establish therapeutic recommendations in the Brazilian reality. It was organized as a work group composed of eight dermatologists from several institutions of the country with experience in the treatment of hidradenitis suppurativa and carried out review on the topic. Recommendations were elaborated and voted by modified Delphi system and statistical analysis of the results was performed. The Brazilian consensus on the clinical approach of hidradenitis suppurativa had the support of the Brazilian Society of Dermatology.
\end{abstract}

Keywords: Anti-bacterial agents; Antibodies, monoclonal; Consensus; Hidradenitis suppurativa

\section{INTRODUCTION}

Hidradenitis suppurativa (HS) is a universally distributed chronic inflammatory condition that leads to a great impairment in the life of those affected, with an estimated prevalence of $1 \%$ to $4 \%$ of the population. ${ }^{1}$ In Brazil, the prevalence is $0.41 \%$, with no difference between the many regions in the country, being more prevalent among adolescents $(0.57 \%)$ and adults $(0.47 \%)$ than in children (less than $0.03 \%$ ), according to a study based on a telephone survey with more than 17,000 people from 87 municipalities. ${ }^{2}$

\section{OBJECTIVE OF THE CONSENSUS}

The objective of this consensus is to inform the physician about HS and provide recommendations on its treatment according to the Brazilian context. It is not a systematic review but a docu- ment that integrates the newest immune-inflammatory concepts, taking into consideration the classification, investigation and treatment based in evidence from the literature, guided by international guidelines and validated by Brazilian specialists with the modified "Delphi" system. ${ }^{3}$ The differences in practice between men, women, adults and children are also one talking point.

To prepare this consensus, a work group made by eight dermatologists was formed with the support of the Brazilian Society of Dermatology, who are experienced in the clinical and surgical treatment of patients with hidradenitis suppurativa, representing the many regions of the country. A systematic review of the clinical treatment of hidradenitis suppurativa and a survey of therapeutic guidelines were performed.

\footnotetext{
Received 07 July 2018.

Accepted 13 September 2018.

* Work conducted at the Sociedade Brasileira de Dermatologia, Rio de Janeiro (RJ), Brazil.

Financial support: None.

Conflict of interest: The members of this council declare they took part in scientific meetings, lectures and/or received support for events of the following pharmaceutical companies: Renata Ferreira Magalhães: Abbvie, Janssen-Cilag, Pfizer, Novartis and Lilly. Maria Cecília Rivitti-Machado: Abbvie and Bayer. Gleison Vieira Duarte: Abbvie, Janssen-Cilag, Leo Pharma, Galderma, Bayer, Pfizer, Novartis and Biolab. Roberto Souto: Abbvie, Novartis, Janssen-Cilag, Pfizer and Lilly. Daniel Holthausen Nunes: Abbvie, Janssen-Cilag, Novartis, Pfizer and Sanofi. Mario Chaves: Abbvie. Sérgio Henrique Hirata has no conflict of interests. Andrea Machado Coelho Ramos: Abbvie, Janssen-Cilag, Novartis and Sanofi.

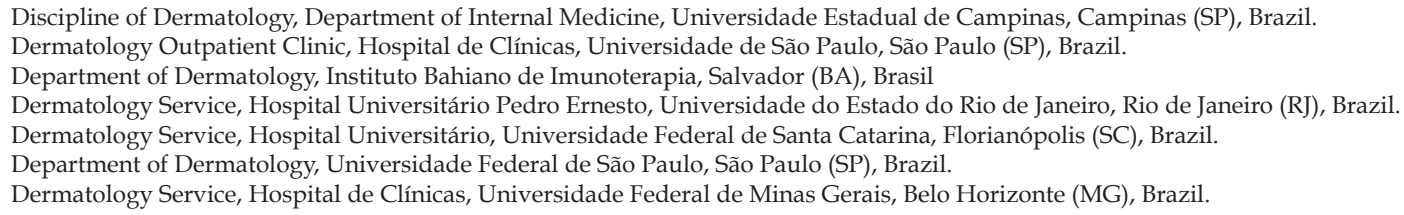


Recommendations based on evidence were established, arranged into a poll system (Survey Monkey ${ }^{\circledR}$ ) and forwarded to the specialists. For the topics "general measures" and "topical treatments" and for the topic "immunobiologics", polls through the modified Delphi system (RAND/UCLA) were conducted, where agreement was indicated with the statements ( $1=$ totally agree; $2=$ partially agree; $3=$ do not agree or disagree; $4=$ partially disagree; $5=$ totally disagree). The recommendations that achieved more than $75 \%$ of agreement among the specialists were included. The remaining were re-evaluated, re-discussed and re-posted for voting for the second time. Data obtained were analyzed statistically. ${ }^{3,4}$ For the topic "systemic treatments", a ranking according to the order of preference among the drugs that should be used for the treatment of HS was asked of the specialists. To verify differences in the specialists' preferences, the Friedman test was used, and the significance level adopted was of $5 \%$. The sample was obtained by nomination and subjected to the randomness test, which resulted in the non-rejection of randomness, with a significance level of $5 \%{ }^{5}$

Data were arranged into tables with levels of evidence (Center of Based Evidence Oxford 2001), grades of recommendation and degree of agreement among the specialists. ${ }^{6}$

\section{DEFINITION}

Hidradenitis suppurativa is a chronic, recurrent inflammatory condition of the hair follicle, that occurs in genetically predisposed individuals and is influenced by environmental factors such as smoking and obesity. It causes a great impact in the quality of life with physical, psychological and socioeconomic sequelae. ${ }^{1}$

The physiopathogenesis of the disease is currently understood as: I) hyperkeratosis and follicular occlusion; II) dilatation of the pilosebaceous unit; III) rupture and release of the follicular contents into the dermis; IV) secondary inflammatory reaction; V) influx of inflammatory cells and release of new cytokines, perpetuating the process (raise in TNF $\alpha$, IL-6, IL-10, IL-12, IL-23 and IL-17); with the formation of abscesses and fistulas. Sex steroids seem to influence the course of the disease with onset after puberty, female predominance and perimenstrual exacerbation; however, their contribution to the pathogenesis is still unclear., ${ }^{1,7-9}$

\section{COMORBIDITIES}

Hidradenitis suppurativa can be associated to many diseases, such as follicular occlusion syndrome (acne conglobata, dissecting cellulitis and pilonidal sinus); auto-inflammatory diseases such as SAPHO (synovitis, acne, pustulosis, hyperostosis and osteitis), PASH (pyoderma gangrenosum, acne and suppurative hidradenitis) and PAPASH (pyogenic arthritis, pyoderma gangrenosum, acne and suppurative hidradenitis) syndromes and genetic syndromes, the most prevalent being Down and KID (keratosis, ichthyosis, deafness) syndromes. It is also frequently associated to inflammatory bowel disease and spondyloarthropathies. It can be accompanied by manifestations of neutrophilic conditions such as pyoderma gangrenosum, Sweet syndrome and erythema nodosum. Psychiatric conditions are highly prevalent in HS patients, such as depression and suicidal ideation. More than half of the patients are obese and present features of metabolic syndrome, including insulin resistance and polycystic ovary syndrome, which are more prevalent in affected females. ${ }^{10-13}$ HS patients are under a higher risk of early severe cardiovascular events and reduced life expectancy than patients with psoriasis and other severe inflammatory diseases. ${ }^{14}$

The dermatologist should be vigilant and inquire about possible symptoms of these entities (joint pains, bone pains, intestinal symptoms, sexual dysfunction, psychiatric symptoms) so that the approach to the HS patient be comprehensive. ${ }^{15}$

\section{DIAGNOSIS}

Diagnosis is clinical in essence, based on the modified criteria of Dessau. For such, it is important to define lesions and typical sites besides recurrence or chronicity, translated by the occurrence of 2 or more episodes in 6 months. ${ }^{1,16}$ For didactic purposes, this consensus suggests the following description for HS lesions:

Nodule: raised, palpable, edematous lesion, larger than $1 \mathrm{~cm}$.

Abscess-like: painful, fluctuant lesion larger than $1 \mathrm{~cm}$ in diameter, with an inflammatory aspect, not necessarily septic.

Tunnel: longitudinal, raised, painful, fluctuant mass, with variable length and depth, ending on the skin surface and occasionally with fluid discharge (pus, blood, serum). This denomination includes fistulas, draining and non-draining sinus tracts.

Typical sites are axillae, inguinal regions, inframammary region and intermammary and gluteal clefts, even though atypical sites can also be involved (face, neck, back, thighs). ${ }^{17}$

Complementary exams such as biopsy and culture of the lesions are indicted in cases of diagnostic uncertainty. ${ }^{18}$ Suspicious chronic lesions can also require malignancy screening. ${ }^{19}$ Imaging studies (ultrasound and nuclear magnetic resonance) can be beneficial for a better characterization of the lesions and/or surgical programming. Ultrasound evaluation can contribute to post-surgery follow-up if recurrence is suspected. ${ }^{20}$

\section{OBJECTIVES OF MEDICAL TREATMENT}

Control the inflammation and intercurrent infections;

Avoid progression to advanced stages with fibrosis and scarring and involvement of extensive and/or multiple areas;

Improve quality of life, particularly in regards to pain and discharge;

Prepare for surgical procedure, reducing inflammation and delimitating the lesion;

Approach extensive, disseminated, ulcerated and/or surgically difficult-to-treat clinical forms;

Treat syndromic cases, in which HS is associated to other conditions such as auto-inflammatory diseases and inflammatory bowel disease.

\section{CLASSIFICATION}

To define the treatment to be established, is important to recognize elementary lesion and adequately classify HS. Many classifications were proposed, but the following classifications were chosen to guide this consensus due to their practicality and ease of use:

Hurley Stages 
Hurley's classification, the oldest one, allows for the prompt and intuitive evaluation but has limitations such as not including the location and number of affected sites, of not reflecting the inflammatory stage and not allowing follow-up (Chart 1). Thus, other classification/staging criteria are necessary to determine the severity of the clinical picture. ${ }^{21,22}$

\section{International Hidradenitis Suppurativa Severity Scoring System (IHS4)}

This system was recently developed and validated by members of the European Hidradenitis Suppurativa Foundation and consists in a simple evaluation that better reflects the severity of the clinical picture:

IHS4 $=$ number of nodules $($ multiplied by 1$)+$ number of abscesses (multiplied by 2) + number of draining tunnels (multiplied by 4$)$;

The total value is stratified as mild (score of 3 or less), moderate (score of 4 to 10) and severe (score of 11 or more). ${ }^{23}$

\section{Hidradenitis suppurativa score (HiSCR)}

This scale was developed with the purpose of being a parameter of evaluation of the clinical response to treatment. The definition proposed of response to treatment (i.e., HiSCR reached) is when there is at least a $50 \%$ reduction in the sum of abscesses and inflammatory nodules, with no increase in the number of abscesses and tunnels with or without inflammatory activity when compared to the baseline count. ${ }^{24}$

\section{Clinical classification}

Besides the severity assessment indexes, hidradenitis should be understood according to its clinical features that can influence the treatment choice. Canoile-Poitrine classification groups cases into axillary-mammary, follicular and gluteal types.. ${ }^{25}$ Van der Zee et al proposed the classification into the regular, conglobata, scarring folliculitis, frictional furuncle, syndromic and ectopic types, suggesting this can even help guide treatment choice. ${ }^{26}$

\section{TREATMENT}

\section{STEP 1}

\section{General measures}

\section{Weight control}

There are studies correlating obesity with the course and severity of HS. The influence of obesity in the process of systemic inflammation and risk of comorbidities is known. In the case of HS, obesity influences the disease directly through mechanical effects

\section{CHART 1: Hurley's classification for hidradenitis suppurativa}

\begin{tabular}{|ll|}
\hline Hurley staging \\
\hline Stage I & $\begin{array}{l}\text { Single or multiple abscesses, without tunnels or } \\
\text { scarring }\end{array}$ \\
Stage II & $\begin{array}{l}\text { Single or multiple isolated recurrent abscesses, } \\
\text { with the formation of tunnels and scarring }\end{array}$ \\
Stage III & $\begin{array}{l}\text { Multiple interconnected tunnels and abscesses } \\
\text { involving at least one whole anatomic region }\end{array}$
\end{tabular}

(friction, rubbing of the hair shaft) and the coexistence of hormonal changes (polycystic ovary syndrome and glucose intolerance). In view of these considerations, weight loss is recommended in the approach of the patient with HS, with or without disease activity. ${ }^{27-30}$

\section{Management of pruritus}

It is not common to ask about pruritus when seeing patients with HS. However, great part of the patients complain of pruritus that can even impair sleep and, consequently, the quality of life. Studies demonstrate that pruritus, as erythema and local pain are considered prodromal symptoms for flares. Pruritus control is recommended with or without disease activity, with the primary goal of improving the quality of life of these patients. ${ }^{31,32}$

\section{Smoking}

Even though there are no randomized studies establishing the causal relationship between smoking and HS, many studies point to a high prevalence of smoking among HS patients, besides increased severity of the disease in those who smoke. Tobacco seems to influence the genetic predisposition for HS, leading to the formation of follicular plugs and the inflammatory process triggered by neutrophils. Smoking cessation is important in the approach of the patient with HS..$^{33-36}$

\section{Friction}

Studies demonstrated the impact that friction has on the stability and distortions of the hair follicle even before the formation of the follicular plug. The predilection of HS to flexural areas is clear, as well as a higher prevalence in obese patients. Restricting the use of tight clothing and/or clothing that causes friction in the areas of predilection for HS lesions is recommended. ${ }^{37,38}$

\section{Local antiseptics}

It is known that HS is an inflammatory disease and when an infectious process occurs it is secondary. There is the hypothesis that follicular occlusion could be a site for bacterial colonization, triggering an exacerbated inflammatory reaction to the local microbiome. Advice on adequate local hygiene should be given, although there is no need to exhaustively remove germs or to use soaps with high concentrations of chlorhexidine. ${ }^{39-43}$

\section{Hair removal}

Laser hair removal leads to the reduction in the number of hair follicles and bacteria in the affected areas. It is an adjuvant therapy for the management of HS, reducing the number of flares and preventing the appearance of new lesions.

Many studies have showed that laser hair removal is effective in the control of HS. A controlled, randomized, prospective study with 22 patients Hurley I to III using Nd:Yag laser demonstrated a $65 \%$ improvement after three monthly treatments. ${ }^{44}$ Another randomized study compared contralateral sites as controls and reduction in HS severity was of $65.3 \%$ and $72.7 \%$ after laser treatment when compared to $7.5 \%$ and $22.9 \%$ for control sites treated topically with $10 \%$ benzoyl peroxide and $1 \%$ clindamycin. ${ }^{45}$ Other lasers, such as diode and intense pulsed light have successful reports in smaller 
series of patients. ${ }^{3}$

\section{Dressings}

HS patients can present with discharge despite adequate treatment, causing psychosocial and physical discomfort due to odor and maceration. Dressing should be adapted to the anatomic location of lesions and have absorbent and non-irritant properties, besides keeping the surface dry and absorb odor. There are no specific dressings used in the treatment of HS nor controlled, randomized studies assessing the use of specific dressings or methods for treating wounds in the treatment of HS. ${ }^{46,47}$

\section{Topical treatments \\ Clindamycin}

One percent clindamycin gel is the only topical antibiotic with randomized studies comparing its efficacy to the use of a systemic medication, tetracycline. There was no difference in efficacy after 3 months of treatment. During the use of topical clindamycin, superficial lesions (pustules, folliculitis) showed better responses when compared to deeper lesions (nodules and abscesses). In view of these considerations, the use of $1 \%$ clindamycin gel in HS lesions is recommended for Hurley stage I or in cases with superficial lesions during exacerbation periods. ${ }^{48-50}$

\section{Fusidic acid}

The use of fusidic acid was evaluated through case reports and one prospective study where Hurley stage I patients were assessed. They were submitted to conservative therapy with fusidic acid, besides local antiseptics until the inflammatory nodules were under control, and more than $70 \%$ of cases achieved control. ${ }^{51}$ Comparing with gentamicin and mupirocin, fusidic acid has a higher minimum inhibitory concentration in the deeper layers of the skin. In view of these considerations, the use of fusidic acid in HS lesions can be useful for Hurley stage I..$^{51,52}$

\section{Other topical antibiotics}

There are not enough studies to support the use of gentamicin or erythromycin in HS. Some studies evaluated the use of gentamicin for the postoperative period with the aim of assessing the rates of recurrence and local complications. A reduction in short-term complications was seen ( 8 weeks); however, there was no success in the long-term rates of recurrence. ${ }^{53}$ The use of gentamicin in HS lesions would only be indicated if the use of other topical antibiotics was not possible.

\section{Benzoyl peroxide associated to clindamycin}

Topical treatment with $10 \%$ benzoyl peroxide gel associated to $1 \%$ clindamycin gel or lotion was compared to the topical treatment associated to Nd-Yag laser hair removal in a controlled, prospective study with 22 Hurley I to III patients. Progressive improvement in the activity of the disease was seen, more markedly during the 4 months of treatment, which was maintained in the post-treatment 2-month follow-up period. The improvement was of $72.7 \%$ on the side treated with laser and $22.9 \%$ on the control side, suggesting that topical treatments improve HS, although less than when associated to laser hair removal. There are no studies with benzoyl peroxide alone. ${ }^{45,46}$

\section{Topical retinoid}

Some specialists suggest the use of adapalene, azelaic acid, antiseptics or other acne treatments can be beneficial; however, evidence is lacking to indicate such treatments. ${ }^{3,54,55}$

\section{Resorcinol cream}

Topical resorcinol was studied in a prospective study. Twelve patients with Hurley I or II HS were instructed to apply 15\% resorcinol cream twice daily on the active HS lesions. In all patients, the use of resorcinol resulted in reduction of pain and reduction in the mean duration of painful abscesses. Topical resorcinol (m-dihydroxybenzene) is an exfoliant with keratolytic, antipruritic and antiseptic activity. It can be useful to shorten the mean duration of a painful nodule or abscess. ${ }^{3,56}$ There are still no controlled, randomized studies on its efficacy.

\section{Intralesional steroid}

Intralesional triamcinolone acetonide in the concentration of 5 to $10 \mathrm{mg} / \mathrm{mL}$ is used for the treatment of acute inflammation and abscesses. It can also be useful for the treatment of refractory nodules and tunnels. Clinical response is fast, within 48 to 72 hours. Well-known adverse events such as atrophy, pigment changes and telangiectasias can occur but, if used in the recommended doses, systemic adverse events are uncommon. This treatment is contraindicated if infection is present. Intralesional steroid injection is seen as beneficial by physicians and patients in the management of HS, reducing pain after 1 day and inflammatory signs after 7 days. ${ }^{3,46,57,58}$

STEP 2

Systemic treatment

Children younger than $\mathbf{1 2}$ years of age

Studies show that $36 \%$ of HS cases occur before 20 years of age; this datum is controversial, ranging from less than $2 \%$ of cases before 11 years of age to $7.6 \%$ before 13 years..$^{59-61}$ However, only studies with low levels of evidence are available for the treatment of HS in the pediatric age group.

The use of systemic antibiotics is based in clinical trials in adults. Different case series of HS in children identified oral erythromycin and clindamycin among the most commonly used antibiotics. Tetracyclines are not recommended in people younger than 10 years of age due to the risk of permanent changes in the color of the teeth. Rifampicin associated to clindamycin can be used in the pediatric group. ${ }^{62}$ Isotretinoin was also frequently described in these series, despite not being the first choice due to the limited effect described in adults. ${ }^{63}$ Regardless of the presence or absence of premature adrenarche in the endocrinological evaluation, antiandrogens such as finasteride ( 1 to $5 \mathrm{mg}$ /day) have been shown to be effective in refractory HS in children. ${ }^{64,65}$ Two case series ( 3 and 5 children) showed efficacy and achievement of remission for variable periods of 5 to 24 months, with few adverse events. Due to the risk of feminization of the fetus, its use is recommended in cases refractory to topical and oral antibiotics, before considering biologic or surgical 
treatment. Finally, the use of botulinum toxin was reported with an initial satisfactory result but recurrence after 6 months. ${ }^{66}$

\section{Women of childbearing age}

Case series comparing women using antiandrogen medications (conjugated contraceptive with cyproterone; spironolactone; spironolactone and cyproterone; 29 cases) versus oral antibiotics (tetracyclines, trimethoprim/sulfamethoxazole; 23 cases) showed a higher response rate in the first group (55\%) when compared to the second group (26\%). ${ }^{67}$ Antiandrogen strategy in women is an interesting option with level of evidence $\mathrm{C}$ and can be indicated for those who fail antibiotic treatments. The ideal antiandrogen regimen is controversial, with no differences in HS responses identified with ethynilestradiol combined with cyproterone or with norgestrel. ${ }^{68}$

Isotretinoin was evaluated in 7 different studies with levels of evidence B and C, and the collective of patients in these studies showed lack of efficacy in $64 \%$. Despite the high percentage of responders in studies with acitretin, with levels of evidence B and C, it is not appropriate to women of childbearing age, and in this situation the choice of isotretinoin over acitretin is justified. ${ }^{69}$

The use of systemic steroids is based in a study with hydrocortisone published in $1958 .^{70}$ The disease responds to high daily doses of prednisone $0.5-0.7 \mathrm{mg} / \mathrm{kg} /$ day, with recurrence after dose reduction. Therefore, systemic steroids are indicated essentially for flares, for short periods of time. However, a publication of a small case series shows that low daily doses for limited periods can be useful for refractory cases, associated to other medications.

Metformin was studied in a case series with 25 individuals (22 of those were females) with a previous history of antibiotic use and 11 of them using isotretinoin. In doses of up to $1.5 \mathrm{~g} /$ day, 19 of these patients showed responses (DLQI and/or Sartorius) in 12 to 24 weeks. ${ }^{71}$

Zinc gluconate is an option for the maintenance treatment in Hurley stages I and II, in a $90 \mathrm{mg}$ dose divided into three doses. The possible impairment in iron and copper absorption and gastrointestinal bleeding can limit its long-term use., ${ }^{3,72}$

Dapsone was evaluated in 3 different studies with level of evidence C, demonstrating a significant response in 35\%, moderate in $21 \%$ and absent in $44 \%$, suggesting its use in patients who fail first- or second-line systemic treamtents. ${ }^{69}$

Data for methotrexate and ciclosporin are not robust and these drugs should be considered as third-line of association for long-term inflammation control.

\section{Non-childbearing age women and men}

Tetracycline 500mg twice daily led to a reduction of approximately $30 \%$ in disease severity but showed no benefits when compared to $1 \%$ topical clindamycin. ${ }^{48}$ The association of clindamycin and rifampicin was tested in 3 case series studies with the $300 \mathrm{mg}$ dose of clindamycin and $600 \mathrm{mg}$ of rifampicin daily for 10 weeks, demonstrating global, pain and Sartorius score improvement. ${ }^{73-75}$

A recent study demonstrated that the association of clindamycin (600 to $1800 \mathrm{mg}$, according to the weight) and ofloxacin (200 to $400 \mathrm{mg}$ ) for a mean observation period of 4.3 months led to comparable results to the association of rifampicin and clindamycin.
Sixty-five patients were treated and $33.8 \%$ had complete response and $24.6 \%$ partial response, regardless on the initial Hurley stage. ${ }^{76}$

The combination of minocycline 100mg daily for 6 months and colchicine $0.5 \mathrm{mg}$ twice daily for 9 months was also reported in a pilot study with 20 patients. More than $90 \%$ of patients had a PGA (Physician Global Assessment) between good and excellent for up to 9 months of observation. ${ }^{77}$

There are reports of improvement in retrospective studies with few patients with dapsone in doses between $25-200 \mathrm{mg}$ /day for at least 3 months, with fast recurrence after discontinuation. ${ }^{78,79}$

The use of isotretinoin for the treatment of HS is questionable. Studies show that $64.4 \%$ of patients are non-responders and those who respond have mild forms (Hurley I). Dose can range between $0.5-1.2 \mathrm{mg} / \mathrm{Kg} /$ day. ${ }^{80-85}$ Acitretin shows higher response rates as demonstrated in a study where 21 out of 32 patients $(65.6 \%)$ had a marked improvement, 8 patients $(25 \%)$ had a moderate improvement and 3 patients $(9.4 \%)$ did not respond to the treatment with daily doses of $0.25-0.88 \mathrm{mg} / \mathrm{kg}$ for 3 to 12 months. ${ }^{86-92}$

\section{STEP 3}

\section{Biologic treatment}

Biologic drugs have a well-established role for the treatment of inflammatory diseases such as rheumatoid arthritis, psoriasis and Crohn's disease. ${ }^{93}$ The first reported case of hidradenitis suppurativa responsive to treatment with infliximab in a patient with Chron's disease was in 2001. ${ }^{94}$ This publication revolutionized the perception of the disease and subsequent studies lead to a change in the paradigm of the pathogenesis and treatment of hidradenitis. TNF-alpha (tumor necrosis factor alpha) is a pro-inflammatory cytokine with a central role in the pathogenesis of hidradenitis suppurativa, as well as IL-1 and IL-17. Also, IL-6, IL-12 and IL-23 have a relevant role. . $^{7,9,9,95-98}$

Cytokines became an important target for inflammation control, integrating the armamentarium employed in the management of hidradenitis suppurativa, what was acknowledged in consensuses, reviews and guidelines for the management of the disease already published in many countries. ${ }^{99-106}$

TNF-alpha blockers, including adalimumab, infliximab and etanercept, were the first biologics studied for the treatment of hidradenitis suppurativa. Among them, adalimumab is the one with more complete studies, with better level of evidence (1B) for the treatment of hidradenitis suppurativa.

\section{ADALIMUMAB}

Adalimumab is a fully humanized monoclonal antibody proteins that target soluble and transmembrane TNF-alpha. ${ }^{93}$

Adalimumab is the only approved medication that is indicated for the treatment of hidradenitis suppurativa. ${ }^{107-109}$ The medication is approved for this indication by the European Medicine Agency and the Food and Drug Administration.

Phase 3 studies, known as PIONEER I and PIONEER II, demonstrated the efficacy of adalimumab for the treatment of hidradenitis suppurativa, superior to placebo. The primary outcome was HiSCR (Hidradenitis Suppurativa Clinical Response) at week 12.

In PIONEER I, 307 patients were selected (154 for placebo; 
153 for adalimumab) and in PIONEER II, 326 (163 for placebo; 163 for adalimumab). The rate of HiSCR achievement at week 12 was significantly higher for patients randomized in the weekly adalimumab group ( $41.8 \%$ vs. $26.0 \%$ in PIONEER I, $p=0.003 ; 58.9 \%$ vs. $27.6 \%$ in PIONEER II, $p<0.001) .{ }^{109}$

At week 36 (period B), a higher rate of HiSCR achievement was observed for all patients that received weekly adalimumab in periods A and B (43.8\% in PIONEER I and $47.1 \%$ in PIONEER II) compared to patients that received weekly adalimumab in period A and were re-randomized for application every 2 weeks $(31.3 \%$ in PIONEER I and $41.5 \%$ in PIONEER II) or placebo (26.5\% in PIONEER I and $41.5 \%$ in PIONEER II) in period B. ${ }^{109}$

Adalimumab was also effective for improving the quality of life of patients with HS. HiSCR rates were maintained long-term and the safety profile in moderate to severe HS patients was similar to that reported for the drug in other indications. ${ }^{109} \mathrm{~A}$ recent study demonstrated that the ratio of patients with reduced infectious events related to the treatment was higher when compared to placebo. ${ }^{110}$

The need for higher induction and maintenance doses to achieve better disease control in comparison to the doses used in rheumatoid arthritis, psoriasis and Crohn's disease is related to a higher inflammatory burden of hidradenitis suppurativa in relation to those diseases. ${ }^{54}$

Adalimumab dosing for the treatment of hidradenitis suppurativa was established with the PIONEER II study and is of $160 \mathrm{mg}$ at day $1,80 \mathrm{mg}$ at day 14 and $40 \mathrm{mg}$ weekly from day 29. The treatment is indicated for a period determined by the treating physician. Once the inflammation is under control, the areas with residual activity or scarring can be excised. Treatment maintenance with adalimumab contributes to reduce recurrences. ${ }^{111}$

\section{INFLIXIMAB}

It is a chimeric antibody formed by human and murine proteins that targets soluble and transmembrane TNF-alpha. ${ }^{93}$ After the initial publication of 2001, many case reports and small series confirmed the value of infliximab for the treatment of hidradenitis suppurativa. Improvement of multiple parameters was demonstrated but appropriate evaluation scales were not used. A placebo controlled, randomized, double-blind clinical trial on the use of infliximab in HS included 38 patients who received infliximab $(5 \mathrm{mg} / \mathrm{kg}$ in weeks 0,2 and 6 and every 8 weeks thereafter) or placebo; after 8 weeks an open-label phase followed, in which those receiving placebo could receive the drug. ${ }^{112}$ It was observed that $26 \%$ of the patients in the group receiving the treatment had a $50 \%$ or more improvement when compared to $5 \%$ in the placebo group. Moreover, scores like DLQI (Dermatology Quality of Life Index), pain and PGA demonstrated an improvement in relation to baseline when compared to the placebo group. Monotherapy with infliximab was well tolerated and a higher number of adverse events occurred in the placebo group. ${ }^{112}$

As well as with adalimumab, better results are achieved with doses of $5 \mathrm{mg} / \mathrm{Kg}$ every month after the induction phase with $5 \mathrm{mg} / \mathrm{Kg}$ at the starting week, week 2 and week $6 .{ }^{113}$ Methotrexa- te can be added to improve efficacy of the treatment with infliximab, particularly in patients with spondyloarthropathies associated to HS. ${ }^{93}$

\section{ETANERCEPT}

It is a fully human fusion protein formed by the TNF-alpha receptor and by the protein component of the immunoglobulin G1 receptor. This protein only binds to soluble TNF-alpha and not to transmembrane. ${ }^{93}$

The first publications pointed towards a benefit of the use of etanercept in the treatment of HS. ${ }^{114-116}$ Subsequently, a study did not show benefits with the use of etanercept 50mg weekly, discouraging subsequent protocols. The studies involved few patients and non-validated evaluation scales, hindering possible conclusions about its employment in the disease.

\section{USTEKINUMAB}

Ustekinumab is a human monoclonal antibody with high affinity for the p40 subunit of IL-12 and IL-23. IL12/23 pathway is implicated in the pathogenesis of hidradenitis suppurativa and, besides, polymorphisms in IL-12 beta- 1 receptor influence the clinical picure. ${ }^{93}$

Ustekinumab was successful for the treatment of hidradenitis suppurativa reported in isolated cases. ${ }^{111,117-120}$ Blok et al reported the use of ustekinumab in 17 patients with moderate to severe HS in a prospective, open-label study with validated outcome measures. Twelve patients completed the study; $82 \%$ of patients showed moderate to significant results. The mean improvement in the modified Sartorius score was of $46.3 \%$ and 7 patients $(41 \%)$ had a significant reduction in DLQI. The medication was administered subcutaneously, in a $45 \mathrm{mg}$ dose or $90 \mathrm{mg}$ if the weight was over $100 \mathrm{~kg}$. The authors noticed that the dose administered was the one approved for psoriasis and that higher doses might be necessary for the treatment of hidradenitis suppurativa, as in Crohn's disease. ${ }^{121}$

\section{ANAKINRA AND CANAKINUMAB}

Anakinra is a recombinant antagonist of IL-1-alpha receptor that competitively binds to IL-1 receptors and prevents the interaction of IL-1 accessory protein with the receptor, resulting in signal blockage. ${ }^{93}$

IL-1 pathway blockers have been used in the treatment of HS, especially in syndromic forms. Anakinra is not available in Brazil. Canakinumab, a IL-1-beta inhibitor, was successfully used for the treatment of HS in sparse case reports. ${ }^{122-124}$

\section{SECUKINUMAB}

Secukinumab is an anti-IL-17A monoclonal antibody that binds to that cytokine preventing its interaction with receptors and inhibiting the inflammatory cascade. Studies demonstrated the importance of this pathway in the pathogenesis of HS. ${ }^{125}$ An extensive and severe case, resistant to multiple treatments was treated with secukinumab and showed a fast and significant response, demonstrating that blockage of IL-17A has a role in the management of HS. ${ }^{126}$ 


\section{APREMILAST}

Apremilast, an inhibitor of phosphodiesterase-4, is a small oral molecule, that showed satisfactory results for the treatment of HS in a small case series and is a subject for protocols for this indication. ${ }^{93}$

\section{BIOLOGICS COMBINED TO OTHER THERAPEUTIC MODALITIES}

Biologic drugs can be used in association to other medications such as antibiotic, hormonal therapies, surgical treatments of cutaneous lesions, etc. ${ }^{109}$

The combination of radical resection with treatment with targeted biologic therapy was evaluated for hidradenitis suppurativa, comparing disease recurrence and progression. The medications used were infliximab and ustekinumab, when the former was not available. Treatment was commenced after surgery, when there were no complications and carried out for a minimum period of 6 months. The authors demonstrated lower recurrence and progression rates in the group treated with biologics for at least 6 months. The protective effect of biologics reduced over time after discontinuation of treatment. ${ }^{111}$ Another study evaluated 68 cases in which biologic treatment was associated to surgery, concluding that the combination of both modalities led to a faster decline in disease acitivity. ${ }^{93}$

\section{TREATMENT OF HIDRADENITIS SUPPURATIVA ASSOCIATED TO OTHER INFLAMMATORY CONDITIONS}

Targeted therapy with biologic drugs can be indicated in cases of hidradenitis suppurativa where there is association with other inflammatory diseases such as pyoderma gangrenosum, severe acne, arthritis, osteitis, spondyloarthropathies, psoriasis, follicular occlusion triad - as the association of hidradenitis suppurativa, acne conglobata, dissecting cellulitis is known (called tetrad when pilonidal sinus is present) and inflammatory bowel disease. Biologic drugs can be indicated for the control of one of the conditions even if the others are under control, prioritizing the treatment of the patient as a whole and not of the individual manifestations.

Manifestations known as paradoxical can subsequently develop in patients with conditions being treated by biologics and changing the biologic drug or associating it to other treatments might be necessary to fully control the clinical manifestations.

\section{RECOMMENDATIONS FOR THE TREATMENT OF HIDRADENITIS SUPPURATIVA ACCORDING TO THE LEVEL OF EVIDENCE, GRADE OF RECOMMENDATION AND DEGREE OF AGREEMENT AMONG SPECIALISTS}

The topics discussed and voted by the experts are indicated in charts 2 and 3, according to level of evidence and degree of recommendation.

It was a consensus among the specialists that measures such as weight loss, smoking cessation, hair removal and local antisepsis should be recommended, with a concordance of $100 \%$.

Topical treatment for isolated and superficial lesions is a possibility, and topical $1 \%$ clindamycin has the best evidence and is incorporated in international guidelines as first line. The use of fusidic acid and 15\% resorcinol is justified in the literature but there is no evidence of the benefit of the use of other topical treatment mo- dalities like benzoyl peroxide and retinoids. The $75 \%$ concordance among the specialists was for the use of clindamycin, fusidic acid and resorcinol. It is important to emphasize that HS lesions have a self-limited course.

The rational use of topical antibiotic is a growing concern due to the risk of bacterial resistance. ${ }^{127-129}$ The recommendation is to use it for a limited time and avoid repeating it. The association with other topicals such as benzoyl peroxide or replacement with resorcinol are a good strategy to minimize the risk.

Regarding intralesional therapies, the concordance among the specialists was of $100 \%$ for the use of triamcinolone acetonide in the case of localized nodules and abscesses with inflammatory signs.

Sulfa and tetracycline substances were indicated as first choice. Among those, the medications trimethoprim/sulfamethoxazole and tetracycline were the most voted.

The order of specialist preference for the drugs used in the treatment of HS for adult men and women of non-childbearing age was as follows: sulfas/tetracyclines, acitretin, clindamycin plus rifampicin, zinc, metformin, finasteride, isotretinoin and systemic steroid. For women of childbearing age, the choices according to the order of preference were: sulfas, tetracyclines, oral contraceptive, systemic steroid, metformin, isotretinoin, clindamycin plus rifampicin, zinc and finasteride. The use of acitretin demands caution due to the risk of teratogenesis. For children younger than 12 years, the specialists' order of preference was: sulfas, isotretinoin, acitretin, finasteride, zinc, systemic steroid and clindamycin plus rifampicin.

To confirm if there was any difference in the specialists' preference regarding the type of medication to be used, the Friedman test was used and the level of significance adopted was of $5 \%$. The results demonstrated that preferences are not similar among specialists.

Therefore, the concordance regarding the use of antibiotics such as sulfas and tetracyclines in the initial approach of moderate to severe HS was of $100 \%$ among the specialists.

There must be caution with the use of rifampicin. ${ }^{130}$ In Brazil and in countries where there is a high prevalence of tuberculosis and Hansen's disease, its use should be discussed with local epidemiological surveillance authorities. These infectious diseases should be screened before starting the treatment. Rifampicin is a first-line drug for the treatment of tuberculosis. The incidence of tuberculosis cases resistant to polychemotherapy has increased worldwide and particularly in countries where the disease has a high prevalence, according to an alert from the World Health Organization (WHO). The association of other antibiotic regimens such as clindamycin and ofloxacin can have similar efficacy. ${ }^{76}$

Systemic treatment with clindamycin plus ofloxacin can be indicated in cases of moderate to severe HS as second-line antibiotic therapy. There was an $87.5 \%$ concordance among specialists for this statement.

The course of antibiotic therapy should be long, for at least 10 to 12 weeks and with optimized doses.

It can be associated with or followed by other medications with an anti-inflammatory or antiandrogen effect. Other immunomodulators such as dapsone, for example, can be considered as 
CHART 2: General skin care measures, topical and intralesional treatments according to the level of evidence and grade of recommendation based on the literature

\begin{tabular}{|lclc|}
\hline Intervention & $\begin{array}{c}\text { Level of evidence/Grade of } \\
\text { recommendation }\end{array}$ & Intervention & $\begin{array}{c}\text { Level of evidence/Grade of } \\
\text { recommendation }\end{array}$ \\
\hline Weight Loss & II/B & Clindamycin & II/B \\
Smoking Cessation & II/B & Erythromycin & V/D \\
Local Antiseptics & IV/C & Fusidic acid & IV/C \\
Hair Removal & I/A & Gentamicin & IV/C \\
Dressings & II/B & Clindamycin + Benzoyl peroxide & IV/D \\
& & Resorcinol & III/C \\
& & Topical Retinoid & IV/C \\
& & Intralesional Steroid & IV/D \\
& & Botulinum Toxin & \\
\end{tabular}

\begin{tabular}{|c|c|c|}
\hline & Intervention & Level of evidence/Grade of recommendation \\
\hline \multicolumn{3}{|l|}{ Oral antibiotics } \\
\hline & Trimethoprim/sulfamethoxazole & $\mathrm{IV} / \mathrm{D}$ \\
\hline & Tetracyclines (tetracycline) & II/B \\
\hline & Clindamycin + rifampicin & III/C \\
\hline & Clindamycin + ofloxacin & III/C \\
\hline \multicolumn{3}{|l|}{ Oral retinoids } \\
\hline & Acitretin & II/C \\
\hline & Isotretinoin & $\mathrm{IV} / \mathrm{D}$ \\
\hline \multicolumn{3}{|l|}{ Antiandrogens } \\
\hline & Metformin & II/B \\
\hline & Finasteride & III/C \\
\hline & Ethynilestradiol & III/C \\
\hline \multicolumn{3}{|c|}{ Anti-inflammatories and immunosuppressants } \\
\hline & Systemic steroid & $\mathrm{IV} / \mathrm{D}$ \\
\hline & Dapsone & III/C \\
\hline & Zinc & III/C \\
\hline \multicolumn{3}{|l|}{ Biologics } \\
\hline & Adalimumab & $\mathrm{I} / \mathrm{A}$ \\
\hline & Infliximab & II/B \\
\hline & Etanercept & $\mathrm{III} / \mathrm{C}$ \\
\hline & Anakinra & $\mathrm{III} / \mathrm{C}$ \\
\hline & Canakinumab & $\mathrm{IV} / \mathrm{D}$ \\
\hline & Ustekinumab & III/D \\
\hline & Secukinumab & $\mathrm{IV} / \mathrm{D}$ \\
\hline & Apremilast & $\mathrm{IV} / \mathrm{D}$ \\
\hline
\end{tabular}

maintenance therapy for cases with frequent flares, avoiding or delaying the repeated use of antibiotics. Systemic steroids can initially contribute to reduce the inflammation but its prolonged use should be avoided due to adverse events and the risk of disease rebound.

Oral retinoids can be an option for the forms associated with acne or clinical forms folliculitis-type. Acitretin was shown to be more effective than isotretinoin but it has restrictions in women of childbearing age.

Patients with moderate to severe hidradenitis suppurativa can be treated with anti-TNF-alpha biologic drugs. These medications can be used in association with surgical treatment of cutaneous lesions. In the forms exceptionally severe associated to other conditions, biologic drugs can be indicated for the control of the manifestations even if the others are under control, prioritizing the treatment of the patient as a whole and not of the manifestations individually.

For all these statements, the concordance among the specialists was of $87.5 \%$ and there was consensus to indicate anti-TNF-alpha biologic drugs for patients with moderate to severe hidradenitis suppurativa. Biologics are alternatives for recurrent cases that do not respond or respond partially to the first interventions.

\section{SURGICAL TREATMENT}

Cases of moderate to severe HS with tunnels and scars typi- 
cal of Hurley stages II and III are indications for surgical treatment. When there is considerable tissue damage, the clinical treatment cannot revert the tissue changes, that becomes a site of recurrent inflammation and secondary infection. ${ }^{131,132}$ Biofilms can form inside the tunnels, which are sometimes epithelialized in their interior, maintaining the inflammatory features of the disease. A literature review showed that biofilms are implicated in many dermatological conditions, prevent wound healing and cause recurrent infections. ${ }^{133}$

Surgery for HS is a challenge for the dermatological surgeon since there are controversies regarding the appropriate technique, extension and reconstruction of the area excised. It is important that the inflammatory process be minimum to demarcate the limits of the lesions and improve surgical and postoperative conditions. ${ }^{132}$

In the acute phases, the procedures should be restricted to abscess incision/drainage for symptoms relief. Deroofing, a technique described by Mullins in 1959, can be performed for localized disease and consists in the removal of the roof of the tunnel using scissors, blade, electrosurgery or $\mathrm{CO}_{2}$ laser, directed by a probe, leaving the clean wound bed to heal for secondary intention. ${ }^{132}$ Van der Zee et al, in 2010, showed that $83 \%$ of 88 Hurley I and II lesions submitted to deroofing had no recurrence in 34 months of follow-up. It is a simple technique that allows for speedy recovery and can be performed in the outpatient setting. ${ }^{134}$

The risk of recurrence is higher with partial simple excision than with wide excision. ${ }^{135}$ Surgical planning should be evaluated case by case, and it is not always possible to remove the whole affected tissue in one single step. Tumescent anesthesia, sedation or general anesthesia should be considered for wide excisions.

In chronic cases, wide excision of the affected area yields better results and lower chances of local recurrence. Removal of all tissues affected should be performed including dermis and subcutaneous tissue and sometimes including the underlying fascia, down to where the lesions extend, besides 1 to $2 \mathrm{~cm}$ lateral margins. If there are doubts regarding the extension of the lesions, ultrasound and/ or nuclear magnetic resonance can contribute to the recognition and demarcation of the affected area. ${ }^{136-138}$

Reconstruction is the real challenge and the rule of simplification also applies to HS surgery. Therefore, secondary intention healing, primary closure, grafts and flaps are considered, in this order. Secondary intention healing has advantages because it reduces the time for surgery and provides good cosmetic and functional results, even though the recovery time is longer. Vacuum therapy (V.A.C) and special dressings contribute to a quicker resolution of the surgical wound. However, in certain situations, coverage is important to avoid exposure of important structures such as nerves and vessels, reduce the risk for secondary infections, prevent retractions and reduce the time for healing in the postoperative period. ${ }^{132}$

Data are variable regarding the risk of recurrence after surgery, according to the anatomical sites treated and the techniques used. Weight and smoking seem to be the main risk factors for local recurrence. $^{139}$

A retrospective study evaluated 84 patients after wide excision, with a total of 253 procedures and mean follow-up of 36 months. Recurrence was observed in $37 \%$ in 6 months on average (genital region was the most susceptible), total remission in $49 \%$ and natural progression of the disease in 13\%. Most patients reported a high level of satisfaction with the results obtained. ${ }^{140}$ A German study retrospectively analyzed Hurley III patients who were submitted to wide excisions and observed that $95 \%$ still had life restrictions related to the disease, although $80 \%$ of them were satisfied with the results. This shows that treatment should be combined and there is room for clinical approach before and after surgery. ${ }^{141}$

Surgery during pharmacological treatment is another controversial matter, particularly considering biologic drugs. Patients who underwent surgery while on a biologic drug had better disease control than those who only had medical treatment in a study with 68 cases of moderate to severe HS. ${ }^{142}$

The use of laser technologies has been appreciated for ablation and destruction of chronic lesions. Carbon dioxide laser $\left(\mathrm{CO}_{2}\right)$ can be used for vaporization and excision. Nodules, abscesses and tunnels can be targeted, leaving healthy tissue in between the lesions treated. This way, the technique can spare the surrounding healthy tissue, with appropriate hemostasis and allow for speedy healing. The reports of the studies show less pain and a more comfortable postoperative period than with traditional surgery. ${ }^{143-146}$ Intense pulsed light can provide favorable results even in Hurley II and III cases according to case series published, even though it has superficial penetration. ${ }^{147,148} \mathrm{Nd}$ :YAG 1064-nm laser can be useful for hair removal, treatment of superficial lesions or associated to other modalities in moderate to severe cases. The study by Tierney et al, prospective, randomized, with 22 patients, consisted of three monthly sessions of the therapy on half of the patients' body, while the other half was only treated with topical antibiotic, demonstrating that the result of the association was considerably better. ${ }^{44}$

\section{FINAL CONSIDERATIONS}

HS is considered to be one of the diseases that impairs the quality of life of affected individuals the most. Current knowledge on its ethiopathogenesis has grown considerably and has confirmed its immune-mediated background. Treatment of the disease in early phases where there is pre-clinical inflammation without structural damage can avoid or reduce the devastating progression to fistulas and scarring, which will require surgical treatment. Thus, early diagnosis, interventions on risk factors such as treating obesity, metabolic and hormonal disturbances and smoking cessation measures when the first signs arise are factors that can interfere with the course and severity of the disease..$^{22}$

The inflammation phase that precedes tissue destruction represents the window of opportunity to adequately approach the disease. Treatment with antibiotics and immunosuppressants can contribute to a better systemic control of the inflammation, its repercussion in other organs and its complications. ${ }^{54}$

HS patients should be screened annually due to the high prevalence of associated diseases and the higher risk of cardiovascular disease. Obesity, diabetes, hypertension, metabolic syndrome, besides inflammatory bowel disease, joint disorders, anxiety and depression, smoking and alcoholism are important conditions that should be investigated. ${ }^{22}$

Clinical and surgical care should be constant since in acute phases, drainage and minor excisions can be necessary and in ad- 


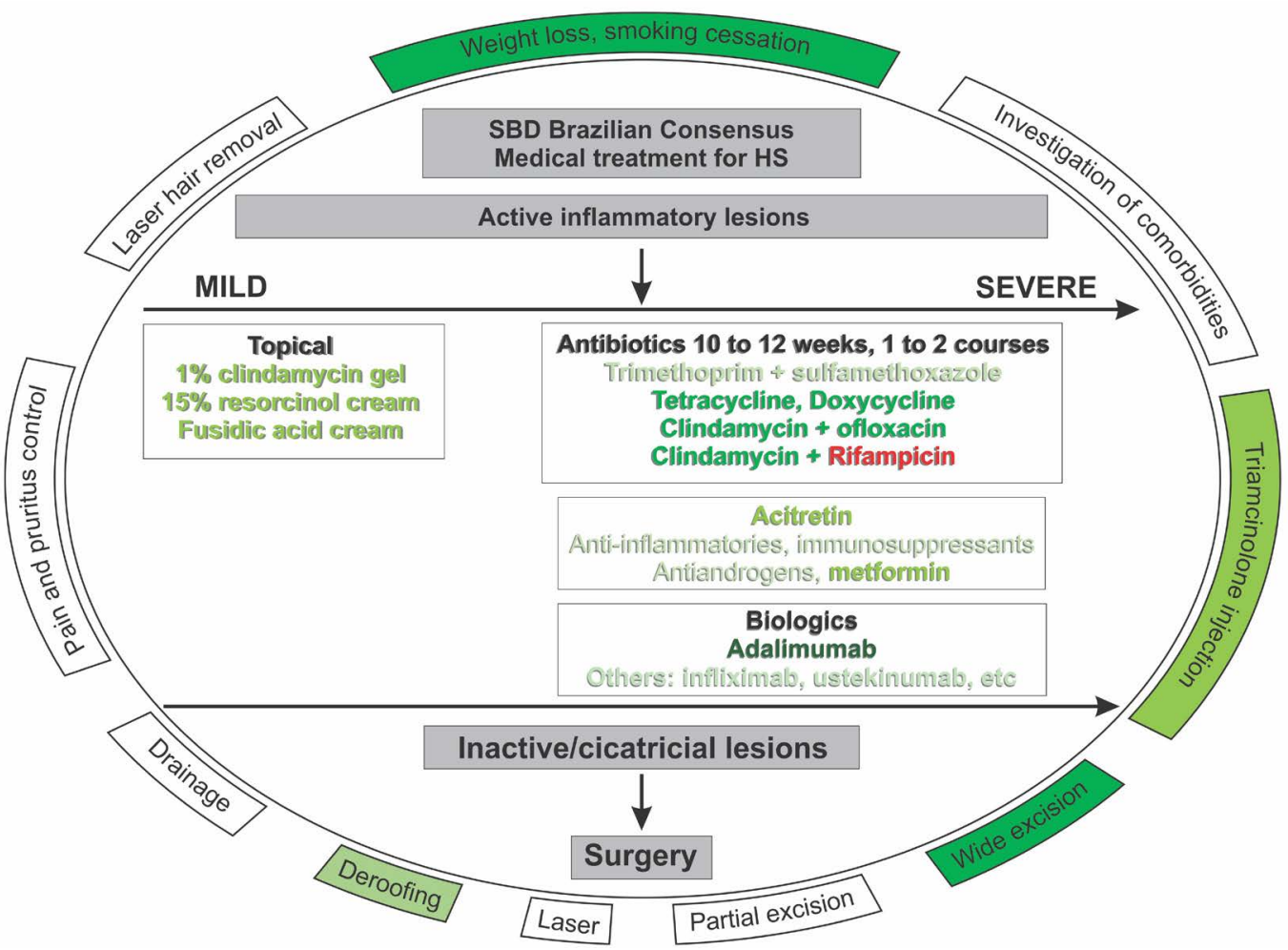

FIGURE 1: Recommendation for treatment of suppurative hidradenitis according to the Brazilian HS Consensus. Interventions in darker tones have higher grades of recommendation, those in red should be considered with caution. Surgical interventions and general measures should be considered throughout patient follow-up. Recommended doses for medications can be adjusted according to medical indication (trimethoprim + sulfamethoxazole $160 \mathrm{mg} / 800 \mathrm{mg}$ bid; tetracycline $500 \mathrm{mg}$ bid (up to $2 \mathrm{~g} /$ day), doxycycline 100 to $200 \mathrm{mg} /$ day, clindamycin 600 to $1800 \mathrm{mg} /$ day + ofloxacin 200 to $400 \mathrm{mg}$ bid, clindamycin 300mg qid + rifampicin 600mg/day, adalimumab subcutaneously 160mg D0, 80mg $\mathrm{D} 14,40 \mathrm{mg} /$ week

vanced phases, established fistulas with frequent suppuration and scarring, that are considered static lesions, require wide excisions. In this sense, multidisciplinary care should be encouraged. ${ }^{142}$

The use of biologics drugs was shown to be effective and safe in HS, indicated for moderate to severe cases that failed conventional treatment. An European consensus, based on a systematic review of the literature and voted by the Delphi system among experts, suggests that the immunobiological treatment should be maintained for at least one year if the patient is a good responder, but if there is no improvement of at least $25 \%$ in HiSCR in the first twelve weeks, this should be reconsidered. ${ }^{99}$

The aim of this consensus is to guide the dermatologist in the approach of the patients with HS in the Brazilian reality, and the authors are open to reevaluation and updating, besides the evaluation of its impact in the dermatology Community (Figure 1).

\section{REFERENCES}

1. Martorell A, García-Martínez FJ, Jiménez-Gallo D, Pascual JC, Pereyra-Rodriguez J, Salgado L, et al. Actualización en hidradenitis supurativa (I): epidemiología, aspectos clínicos y definición de severidad de la enfermedad. Actas Dermosifiliogr. 2015;106:703-15

2. lanhez M, Schmitt JV, Miot HA. Prevalence of hidradenitis suppurativa in Brazil: a population survey. Int J Dermatol. 2018;57:618-20.
3. Gisondi P, Altomare G, Ayala F, Conti A, Dapavo P, De Simone C, et al. Consensus on the management of patients with psoriatic arthritis in a dermatology setting. $J$ Eur Acad Dermatol Venereol. 2018;32:515-28.

4. Canete JD, Daudén E, Queiro R, Aguilar MD, Sánches-Carzo JL, Carrascosa, Puig L, et al. Elaboración mediante el metodo Delphi de recomendaciones para el manejo coordinado (reumatólogo/dermatólogo de la artritis psoriásica. Actas 
Dermassifiliogr. 2014;105:216-32.

5. Friedman M. The use of ranks to avoid the assumption of normality implicit in the analysis of variance. Journal of the American Statistical Association. 1937;32: 675-701.

6. Cebm.net [Internet]. Centre for Evidence Based Medicine (CEBM). Oxford Center for Evidence-based Medicine - Levels of Evidence (March 2009). Oxford: CEBM; 2012. [cited 2018 Jan 1]. Available from: https://www.cebm.net/2009/06/oxfordcentre-evidence-based-medicine-levels-evidence-march-2009/

7. Gill L, Williams M, Hamzavi I. Update on hidradenitis suppurativa: connecting the tracts. F1000Prime Rep. 2014;6:112

8. Kelly G. Prens EP. Inflammatory Mechanisms in Hidradenitis Suppurativa Dermatol Clin. 2016;34:51-8.

9. Prens E, Deckers I. Pathophysiology of hidradenitis suppurativa : An update. J Am Acad Dermatol. 2015;73(5 Suppl 1):S8-11.

10. Fimmel S, Zouboulis CC. Comorbidities of hidradenitis suppurativa (acne inversa). Dermatoendocrinol. 2010:2:9-16.

11. Kohorst JJ, Kimball AB, Davis MD. Systemic associations of hidradenitis suppurativa. J Am Acad Dermatol. 2015;73(5 Suppl 1):S27-35.

12. Miller IM, McAndrew RJ, Hamzavi I. Prevalence, risk factors, and comorbidities of hidradenitis suppurativa. Dermatol Clin. 2016:34:7-16.

13. Gold DA, Reeder VJ, Mahan MG, Hamzavi IH. The prevalence of metabolic syndrome in patients with hidradenitis suppurativa. J Am Acad Dermatol. 2014;70:699-703.

14. Egeberg A, Gislason GH, Hansen PR. Risk of major adverse cardiovascular events and all-cause mortality in patients with hidradenitis suppurativa. JAMA Dermatol. 2016;152:429-34.

15. Wolkenstein P, Loundou A, Barrau K, Auquier P, Revuz J; Quality of Life Group of the French Society of Dermatology. Quality of life impairment in hidradenitis suppurativa: a study of 61 cases. J Am Acad Dermatol. 2007;56:621-3.

16. Lipsker D, Severac F, Freysz M, Sauleau E, Boer J, Emtestam L, et al. The ABC of Hidradenitis Suppurativa: A Validated Glossary on how to Name Lesions. Dermatology. 2016;232:137-42.

17. van der Zee HH, Laman JD, Boer J, Prens EP. Hidradenitis suppurativa: viewpoin on clinical phenotyping, pathogenesis and novel treatments. Exp Dermatol. 2012;21:735-9.

18. Thomas C, Rodby KA, Thomas J, Shay E, Antony AK. Recalcitrant Hidradenitis Suppurativa: An investigation of demographics, surgical management, bacterial isolates, pharmacologic intervention, and patient-reported health outcomes. Am Surg. 2016;82:362-8

19. Pena ZG, Sivamani RK, Konia TH, Eisen DB. Squamous cell carcinoma in the setting of chronic hidradenitis suppurativa; report of a patient and update of the literature. Dermatol Online J. 2015;21. pii: 13030/qt9q9707dp.

20. Martorell A, Wortsman X, Alfageme F, Roustan G, Arias-Santiago S, Catalano O, et al. Ultrasound Evaluation as a Complementary Test in Hidradenitis Suppurativa: Proposal of a Standarized Report. Dermatol Surg. 2017;43:1065-73.

21. Zouboulis CC, Del Marmol V, Mrowietz U, Prens EP, Tzellos T, Jemec GB. Hidradenitis Suppurativa / Acne Inversa: Criteria for diagnosis, severity assessment, classification and disease evaluation. Dermatology. 2015;231:184-90.

22. Zouboulis CC, Desai N, Emtestam L, Hunger RE, loannides D, Juhász I, et al. European $\mathrm{S} 1$ guideline for the treatment of hidradenitis suppurativa/acne inversa. J Eur Acad Dermatol Venereol. 2015;29:619-44.

23. Zouboulis CC, Tzellos T, Kyrgidis A, Jemec GBE, Bechara FG, GiamarellosBourboulis EJ, et al. Development and Validation of the International Hidradenitis Suppurativa Severity Score System (IHS4), a novel dynamic scoring system to assess HS severity. Br J Dermatol. 2017;177:1401-9.

24. Kimball AB, Jemec GB, Yang M, Kageleiry A, Signorovitch JE, Okun MM, et al Assessing the validity, responsiveness and meaningfulness of the Hidradenitis Suppurativa Clinical Response (HiSCR) as the clinical endpoint for hidradenitis suppurativa treatment. Br J Dermatol. 2014;171:1434-42.

25. Canoui-Poitrine F, Le Thuaut A, Revuz JE, Viallette C, Gabison G, Poli F, et al. Identification of three hidradenitis suppurativa phenotypes: latent class analysis of a cross-sectional study. J Invest Dermatol. 2013:133:1506-11

26. van der Zee HH, Jemec GB. New insights into the diagnosis of hidradenitis suppurativa: clinical presentations and phenotypes. J Am Acad Dermatol. 2015;73(Suppl 1):S23-6.

27. Melnik BC, John SM, Chen W, Plewig G. Thelper 17 cell/regulatory T-cell imbalance in hidradenitis suppurativa/acne inversa: the link to hair follicle dissection, obesity, smoking and autoimmune comorbidities. Br J Dermatol. 2018;179:260-272.

28. Boer J. Resolution of hidradenitis suppurativa after weight loss by dietary measures, especially on frictional locations. J Eur Acad Dermatol Venereol. 2016;30:895-6.

29. Thomas CL, Gordon KD, Mortimer PS. Rapid resolution of hidradenitis suppurativa after bariatric surgical intervention. Clin Exp Dermatol. 2014;39:315-7.

30. Kromann CB, Ibler KS, Kristiansen VB, Jemec GB. The influence of body weight on the prevalence and severity of hidradenitis suppurativa. Acta DermVenereol. 2014;94:553-7.

31. Vossen ARJV, Schoenmakers A, van Straalen KR, Prens EP, van der Zee HH. Assessing Pruritus in Hidradenitis Suppurativa: A Cross-Sectional Study. Am J Clin Dermatol. 2017:18:687-95

32. Ring HC, Theut Riis P, Zarchi K, Miller IM, Saunte DM, Jemec GB. Prodromal symptoms in hidradenitis suppurativa. Clin Exp Dermatol. 2017:42:261-265.

33. Sartorius K, Emtestam L, Jemec GB, Lapins J. Objective scoring of hidrade- nitis suppurativa reflecting the role of tobacco smoking and obesity. $\mathrm{Br} \mathrm{J}$ Dermatol. 2009;161:831-9.

34. König A, Lehmann C, Rompel R, Happle R. Cigarette smoking as a triggering factor of hidradenitis suppurativa. Dermatology. 1999;198:261-4.

35. Kromann CB, Deckers IE, Esmann S, Boer J, Prens EP, Jemec GB. Risk factors, clinical course and long-term prognosis in hidradenitis suppurativa: a crosssectional study. Br J Dermatol. 2014;171:819-24.

36. Margesson LJ, Danby FW. Hidradenitis suppurativa. Best Pract Res Clin Obstet Gynaecol. 2014;28:1013-27.

37. Boer J. Should hidradenitis suppurativa be included in dermatoses showing koebnerization? Is it friction or fiction? Dermatology. 2017;233:47-52.

38. Boer J, Nazary M, Riis PT. The Role of mechanical stress in hidradenitis suppurativa. Dermatol Clin. 2016;34:37-43.

39. Hessam S, Sand M, Meier NM, Gambichler T, Scholl L, Bechara FG. Combination of oral zinc gluconate and topical triclosan: An anti-inflammatory treatment modality for initial hidradenitis suppurativa. J Dermatol Sci. 2016;84:197-202.

40. Schena D, Papagrigoraki A, Girolomoni G. Sensitizing potential of triclosan and triclosan-based skin care products in patients with chronic eczema. Dermatol Ther. 2008;21(Suppl 2):S35-8

41. Krbec AC. Current understanding and management of hidradenitis suppurativa. J Am Acad Nurse Pract. 2007:19(5):228-34.

42. Asgeirsson T, Nunoo R, Luchtefeld MA. Hidradenitis suppurativa and pruritus ani. Clin Colon Rectal Surg. 2011;24:71-80.

43. Dessinioti C, Zisimou C, Tzanetakou V, Ntritsos G, Kontochristopoulos G, Antoniou C. A retrospective institutional study of the association of smoking with the severity of hidradenitis suppurativa. J Dermatol Sci. 2017:87:206-207.

44. Tierney E, Mahmoud BH, Hexsel C, Ozog D, Hamzavi I. Randomized control trial for the treatment of hidradenitis suppurativa with a neodymium-doped yttrium aluminium garnet laser. Dermatol Surg. 2009;35:1188-98.

45. Mahmoud BH, Tierney E, Hexsel CL, Pui J, Ozog DM, Hamzavi IH. Prospective controlled clinical and histopathologic study of hidradenitis suppurativa treated with the long-pulsed neodymium: yttrium-aluminum-garnet laser. J Am Acad Dermatol. 2010;62:637-45.

46. van der Zee HH, Gulliver WP. Medical treatments of hidradenitis suppurativa: more options, less evidence. Dermatol Clin. 2016:34:91-6.

47. Alavi A, Kirsner RS. Local wound care and topical management of hidradenitis suppurativa. J Am Acad Dermatol. 2015;73(Suppl 1):S55-61

48. Jemec GB, Wendelboe P. Topical clindamycin versus systemic tetracycline in the treatment of hidradenitis suppurativa. J Am Acad Dermatol. 1998:39:971-4.

49. Ingram JR, McPhee M. Management of hidradenitis suppurativa: a UK survey of current practice. Br J Dermatol. 2015:173:1070-2.

50. Jemec GB. Clinical practice. Hidradenitis suppurativa. N Engl J Med. 2012;366:158-64.

51. Shirah BH, Shirah HA. Effective modified conservative tissue preserving protocol to treat stage I axillary hidradenitis suppurativa: a prospective cohort study of 627 patients with five years follow-up. J Dermatolog Treat. 2017:28:458-463.

52. Schöfer H, Simonsen L. Fusidic acid in dermatology: an updated review. Eur J Dermatol. 2010:20:6-15.

53. Buimer MG, Ankersmit MF, Wobbes T, Klinkenbijl JH. Surgical treatment of hidradenitis suppurativa with gentamicin sulfate: a prospective randomized study. Dermatol Surg. 2008;34:224-7.

54. Martorell A, Caballero A, González Lama Y, Jiménez-Gallo D, Lázaro Serrano M, Miranda J, et al. Management of patients with hidradenitis suppurativa. Actas Dermosifiliogr. 2016;107(Suppl 2):S32-42.

55. Ingram JR, Woo PN, Chua SL, Ormerod AD, Desai N, Kai AC, et al. Interventions for hidradenitis suppurativa: a Cochrane systematic review incorporating GRADE assessment of evidence quality. Br J Dermatol. 2016:174:970-8.

56. Boer J, Jemec GB. Resorcinol peels as a possible self-treatment of painful nodules in hidradenitis suppurativa. Clin Exp Dermatol. 2010;35:36-40.

57. Martorell A, García FJ, Jiménez-Gallo D, Pascual JC, Pereyra-Rodríguez J, Salgado $L$, et al. Actualización en hidradenitis supurativa (III): aspectos terapéuticos. Actas Dermosifiliogr. 2015;106: 697-778 
58. Jemec GBE, Revuz J, Leyden J. Hidradenitis Suppurativa. Berlin: Springer-Verlag; 2006. p.138- 40.

59. Palmer RA, Keefe M. Early-onset hidradenitis suppurativa. Clin Exp Dermatol. 2001:26:501-3.

60. Scheinfeld N. Hidradenitis Suppurativa in prepubescent and pubescent children. Clin Dermatol. 2015;33:316-9.

61. Deckers IE, van der Zee HH, Boer J, Prens EP. Correlation of early onset hidradenitis suppurativa with stronger genetic susceptibility and more widespread involvement. J Am Acad Dermatol. 2015;72:485-8.

62. Mikkelsen PR, Jemec GB. Hidradenitis suppurativa in children and adolescents: a review of treatment options. Paediatr Drugs. 2014;16:483-9.

63. Stojkovic-Filipovic JM, Gajic-Veljic MD, Nikolic M. Prepubertal onset of hidradenitis suppurativa in a girl: A case report and literature review. Indian J Dermatol Venereol Leprol. 2015;81:294-8.

64. Liy-Wong C, Pope E, Lara-Corrales I. Hidradenitis suppurativa in the pediatric population. J Am Acad Dermatol. 2015;73(Suppl 1):S36-41.

65. Randhawa HK, Hamilton J, Pope E. Finasteride for the treatment of hidradenitis suppurativa in children and adolescents. JAMA Dermatol. 2013;149:732-5.

66. Feito-Rodríguez M, Sendagorta-Cudós E, Herranz-Pinto P, de Lucas-Laguna R. Prepubertal hidradenitis suppurativa successfully treated with botulinum toxin $\mathrm{A}$. Dermatol Surg. 2009;35:1300-2.

67. Danby FW. Current concepts in the management of hidradenitis suppurativa in children. Curr Opin Pediatr. 2015;27:466-72.

68. Mortimer PS, Dawber RP, Gales MA, Moore RA. A double-blind crossover trial of cyproterone acetate in females with hidradenitis suppurativa. $\mathrm{Br} \mathrm{J}$ Dermatol. 1986;115:263-8.

69. Blok JL, van Hattem S, Jonkman MF, Horváth B. Systemic therapy with immunosuppressive agents and retinoids in hidradenitis suppurativa: a systematic review. Br J Dermatol. 2013;168:243-52.

70. Danto JL. Preliminar y studies of the effect of hydrocortisone on hidradenitis suppurativa. J Invest Dermatol. 1958;31:299-300.

71. Verdolini R, Clayton N, Smith A, Alwash N, Mannello B. Metformin for the treatment of hidradenitis suppurativa: A little help along the way. J Eur Acad Dermatol Venereol. 2013:27:1101-8.

72. Brocard A, Knol AC, Khammari A, Dréno B. Hidradenitis suppurativa and zinc: a new therapeutic approach. A pilot study. Dermatology. 2007:214:325-7.

73. Gener G, Canoui-Poitrine F, Revuz JE, Faye 0, Poli F, Gabison G, et al. Combination therapy with clindamycin and rifampicin for hidradenitis suppurativa: a series of 116 consecutive patients. Dermatology. 2009;219:148-54.

74. Mendonça CO, Griffiths CE. Clindamycin and rifampicin combination therapy for hidradenitis suppurativa. Br J Dermatol. 2006;154:977-8.

75. van der Zee HH, Boer J, Prens EP, Jemec GB. The effect of combined treatment with oral clindamycin and oral rifampicin in patients with hidradenitis suppurativa. Dermatology. 2009;219:143-7

76. Delaunay J, Villani AP, Guillem P, Tristan A, Boibieux A, Jullien D. Oral ofloxacin and clindamycin as an alternative to the classic rifampicin clindamycin in hidradenitis suppurativa: retrospective analysis of 65 patients. $\mathrm{Br} \mathrm{J}$ Dermatol. 2018:178:e15-e16.

77. Armyra K, Kouris A, Markantoni V, Katsambas A, Kontochristopoulos G. Hidradenitis suppurativa treated with tetracycline in combination with colchicin: a prospective series of 20 patients. Int J Dermatol. 2017:56:346-50.

78. Yazdanyar S, Boer J, Ingvarsson G, Szepietowski JC, Jemec GB. Dapsone therapy for hidradenitis suppurativa: a series of 24 patients. Dermatology. 2011;222:342-6.

79. Kaur MR, Lewis HM. Hidradenitis suppurativa treated with dapsone: a case series of five patients. J Dermatolog Treat. 2006;17:211-3.

80. Soria A, Canoui-Poitrine F, Wolkenstein P, Poli F, Gabison G, Pouget F, et al. Absence of efficacy of oral isotretinoin in hidradenitis suppurativa: a retrospective study based on patients' outcome assessment. Dermatology. 2009;218:134-5.

81. Boer J, van Gemert MJ. Long-term results of isotretinoin in the treatment of 68 patients with hidradenitis suppurativa. J Am Acad Dermatol. 1999;40:73-6.

82. Brown CF, Gallup DG, Brown VM. Hidradenitis suppurativa of the ano- genital region: response to isotretinoin. Am J Obstet Gynecol. 1988:158:12-5.

83. Dicken $\mathrm{CH}$, Powell ST, Spear KL. Evaluation of isotretinoin treatment of hidradenitis suppurativa. J Am Acad Dermatol. 1984;11:500-2.

84. Jones DH, Cunliffe WJ, King K. Hidradenitis suppurativa-lack of success with 13-cis-retinoic acid. Br J Dermatol. 1982;107:252

85. Norris JF, Cunliffe WJ. Failure of treatment of familial widespread hidradenitis suppurativa with isotretinoin. Clin Exp Dermatol. 1986;11:579-83.

86. Boer J, Nazary M. Long-term results of acitretin therapy for hidradenitis suppurativa. Is acne inversa also a misnomer? Br J Dermatol. 2011;164:170-5.

87. Matusiak L, Bieniek A, Szepietowski JC. Acitretin treatment for hidradenitis suppurativa: a prospective series of 17 patients. Br J Dermatol. 2014;171:170-4.
88. Chow ET, Mortimer PS. Successful treatment of hidradenitis suppurativa and retroauricular acne with etretinate. Br J Dermatol. 1992:126:415

89. Hogan DJ, Light MJ. Successful treatment of hidradenitis suppurativa with acitretin. J Am Acad Dermatol. 1988:19:355-6.

90. Scheman AJ. Nodulocystic acne and hidradenitis suppurativa treated with acitretin: a case report. Cutis. 2002;69:287-8.

91. Forbat E, Ali FR, Al-Niaimi F. Dermatological indications for the use of isotretinoin beyond acne. J Dermatolog Treat. 2018;29:698-705.

92. Jemec GB. Long-term results of isotretinoin in the treatment of 68 patients with hidradenitis suppurativa. J Am Acad Dermatol. 1999;41:658.

93. Shanmugam VK, Zaman NM, McNish S, HantFN. Review of the currentimmunologic therapies for Hidradenitis suppurativa. Int J Rheumatol. 2017;2017:8018192

94. Martínez F, Nos P, Benlloch S, Ponce J. Hidradenitis suppurativa and Crohn's disease: response to treatment with infliximab. Inflamm Bowel Dis. 2001;7:323-6.

95. Hoffman LK, Tomalin LE, Schultz G, Howell MD, Anandasabapathy N, Alavi A, et al. Integrating the skin and blood transcriptomes and serum proteome in hidradenitis suppurativa reveals complement dysregulation and a plasma cell signature. PLOS One. 2018;13:e0203672.

96. Bechara FG, Sand M, Skrygan M, Kreuter A, Altmeyer P, Gambichler T. Acne inversa: evaluating antimicrobial peptides and proteins. Ann Dermatol. 2012;24:393-7.

97. Xu H, Xiao X, He Y, Zhang X, Li C, Mao Q, et al. Increased serum interleukin-6 levels in patients with hidradenitis suppurativa. Postepy Dermatol Alergol. 2017;34:82-4.

98. Napolitano M, Megna M, Timoshchuk EA, Patruno C, Balato N, Fabbrocini G, et al. Hidradenitis suppurativa: from pathogenesis to diagnosis and treatment. Clin Cosmet Investig Dermatol. 2017;10:105-15.

99. Zouboulis CC, Bechara FG, Dickinson-Blok JL, Gulliver W, Horváth B, Hughes R, et al. Hidradenitis suppurativa/acne inversa: A practical framework for treatment optimization systematic review and recommendations from the HS ALLIANCE working group. J Eur Acad Dermatol Venereol. 2018. doi: 10.1111/jdv.15233. [Epub ahead of print]

100. Megna M, Bettoli V, Chimenti S, Chiricozzi A, Naldi L, Virgili A, et al. Hidradenitis suppurativa: guidelines of the Italian Society of Dermatology and Venereology (SIDeMaST) for the use of anti-TNF- $\alpha$ agents. G Ital Dermatol Venereol. 2015;150:731-9.

101. Lee RA, Eisen DB. Treatment of hidradenitis suppurativa with biologic medications. J Am Acad Dermatol. 2015;73(Suppl 1):S82-8.

102. Hunger RE, Laffitte E, Läuchli S, Mainetti C, Mühlstädt M, Schiller P, et al. Swiss Practice Recommendations for the Management of Hidradenitis Suppurativa/Acne Inversa. Dermatology. 2017;233:113-9.

103. Alavi A, Lynde C, Alhusayen R, Bourcier M, Delorme I, George R, et al. Approach to the Management of Patients With Hidradenitis Suppurativa: A Consensus Document. J Cutan Med Surg. 2017;21:513-24.

104. Vekic DA, Cains GD. Hidradenitis suppurativa - Management, comorbidities and monitoring. Aust Fam Physician. 2017;46:584-8.

105. Arenbergerová M, Dahmen RA, Arenberger P. Hidradenitis suppurativa - symptoms, diagnostics, and therapy. Cas Lek Cesk. 2017;156:127-132.

106. Ingram JR. Interventions for Hidradenitis Suppurativa: Updated Summary of an Original Cochrane Review. JAMA Dermatol. 2017;153:458-9

107. Adalimumabe (Humira). [Bula]: Importado por: AbbVie Farmacêutica Ltda. Fabricado por Vetter Pharma-Fertigung GmbH \& Co. KG Ravensburg, Alemanha.

108. Kimball AB, Kerdel F, Adams D, Mrowietz U, Gelfand JM, Gniadecki R, et al. Adalimumab for the treatment of moderate to severe Hidradenitis suppurativa: a parallel randomized trial. Ann Intern Med. 2012;157:846-55.

109. Kimball AB, Okun MM, Williams DA, Gottlieb AB, Papp KA, Zouboulis CC,et al. Two Phase 3 Trials of Adalimumab for Hidradenitis Suppurativa. N Engl J Med. 2016:375:422-34.

110. Giamarellos-Bourboulis EJ, Sobell J, Ryan C, Wolkenstein PJ, Geng Z, Mulder GD. Infection-free clinical response among patients with hidradenitis suppurativa who were treated with adalimumab: results from two phase 3 studies. Wounds. 2017;29:E98-E102.

111. DeFazio MV, Economides JM, King KS, Han KD, Shanmugam VK, Attinger CE, et al. Outcomes after combined radical resection and targeted biologic therapy for the management of recalcitrant hidradenitis suppurativa. Ann Plast Surg. 2016;77:217-22.

112. Grant A, Gonzalez T, Montgomery MO, Cardenas V, Kerdel FA. Infliximab therapy for patients with moderate to severe hidradenitis suppurativa: a randomized, doubleblind, placebo-controlled crossover trial. J Am Acad Dermatol. 2010;62:205-17.

113. Moriarty B, Jiyad Z, Creamer D. Four-weekly infliximab in the treatment of severe hidradenitis suppurativa. Br J Dermatol. 2014;170:986-7.

114. Cusack C, Buckley C. Etanercept: effective in the management of hidradenitis suppurativa. Br J Dermatol. 2006;154:726-9.

115. Giamarellos-Bourboulis EJ, Pelekanou E, Antonopoulou A, Petropoulou H, Baziaka F, Karagianni V, et al. An open-label phase II study of the safety and 
efficacy of etanercept for the therapy of hidradenitis suppurativa. Br J Dermatol. 2008;158:567-72

116. Sotiriou E, Apalla Z, Ioannidos D. Etanercept for the treatment of hidradenitis suppurativa. Acta Derm Venereol. 2009;89:82-3.

117. Gulliver WP, Jemec GB, Baker KA. Experience with ustekinumab for the treatment of moderate to severe hidradenitis suppurativa. J Eur Acad Dermatol Venereol. 2012;26:911-4.

118. Sharon VR, Garcia MS, Bagheri S, Goodarzi H, Yang C, Ono Y, et al. Management of recalcitrant hidradenitis suppurativa with ustekinumab. Acta Derm Venereol. 2012:92:320-1.

119. Baerveldt EM, Kappen JH, Thio HB, van Laar JA, van Hagen PM, Prens EP. Successful long-term triple disease control by ustekinumab in a patient with Behcet's disease, psoriasis and hidradenitis suppurativa. Ann Rheum Dis. 2013;72:626-7.

120. Santos-Pérez MI, García-Rodicio S, Del Olmo-Revuelto MA, Pozo-Román T. Ustekinumab for hidradenitis suppurativa: a case report. Actas Dermosifiliogr. 2014;105:720-2

121. Blok JL, Li K, Brodmerkel C, Horvátovich P, Jonkman MF, Horváth B. Ustekinumab in hidradenitis suppurativa: clinical results and a search for potential biomarkers in serum. Br J Dermatol. 2016;174:839-46.

122. Jaeger $T$, Andres C, Grosber M, Zirbs M, Hein R, Ring J, et al. Pyoderma gangrenosum and concomitant hidradenitis suppurativa--rapid response to canakinumab (anti-IL-1 $\beta$ ). Eur J Dermatol. 2013;23:408-10.

123. Galimberti RL, Vacas AS, Bollea Garlatti ML, Torre AC. The role of interleukin- $1 \beta$ in pyoderma gangrenosum. JAAD Case Rep. 2016;2:366-8.

124. Houriet C, Seyed Jafari SM, Thomi R, Schlapbach C, Borradori L, Yawalkar N, et al . Canakinumab for Severe Hidradenitis Suppurativa: Preliminary Experience in 2 Cases. JAMA Dermatol. 2017;153:1195-7.

125. Matusiak Ł, Szczęch J, Bieniek A, Nowicka-Suszko D, Szepietowski JC. Increased interleukin (IL)-17 serum levels in patients with hidradenitis suppurativa: Implications for treatment with anti-IL-17 agents. J Am Acad Dermatol. 2017;76:670-5.

126. Thorlacius $L$, Theut Riis P, Jemec GBE. Severe hidradenitis suppurativa responding to treatment with secukinumab: a case report. Br J Dermatol. 2018;179:182-185.

127. Cunliffe WJ, Holland KT, Bojar R, Levy SF. A randomized, double-blind comparison of a clindamycin phosphate/benzoyl peroxide gel formulation and a matching clindamycin gel with respect to microbiologic activity and clinical efficacy in the topical treatment of acne vulgaris. Clin Ther. 2002;24:1117-33.

128. Leibovici L, Paul M, Garner P, Sinclair DJ, Afshari A, Pace NL, et al. Addressing resistance to antibiotics in systematic reviews of antibiotic interventions. J Antimicrob Chemother. 2016;71:2367-9.

129. Fischer AH, Haskin A, Okoye GA. Patterns of antimicrobial resistance in lesions of hidradenitis suppurativa. J Am Acad Dermatol. 2017;76:309-313.e2

130. Albrecht J, Mehta S, Bigby M. Development of resistance to Mycobacterium tuberculosis is manageable in hidradenitis suppurativa. Response to treatment of hidradenitis suppurativa with rifampicin: have we forgotten tuberculosis? $\mathrm{Br} \mathrm{J}$ Dermatol. 2018:178:300.
131. Muzy G, Crocco El, Alves RO. Hidradenite supurativa: atualização e revisão de suas modalidades terapêuticas. Surg Cosm Dermatol. 2014;6:206-12.

132. Scuderi N, Monfrecola A, Dessy LA, Fabbrocini G, Megna M, Monfrecola G. Medical and Surgical Treatment of Hidradenitis Suppurativa: A Review. Skin Appendage Disord. 2017;3:95-110.

133. Kravvas G, Veitch D, Al-Niaimi F. The increasing relevance of biofilms in common dermatological conditions. J Dermatolog Treat. 2018;29:202-7.

134. van der Zee HH, Prens EP, Boer J. Deroofing: a tissue-saving surgical technique for the treatment of mild to moderate hidradenitis suppurativa lesions. J Am Acad Dermatol. 2010;63:475-80

135. Büyükașik 0, Hasdemir AO, Kahramansoy N, Cöl C, Erkol H. Surgical approach to extensive hidradenitis suppurativa. Dermatol Surg. 2011;37:835-42.

136. Lixia ZE. Hidradenitis suppurativa: surgical and other management techniques Dermatol Surg. 2012;38:517-36.

137. Harrison BJ, Mudge M, Hughes LE. Recurrence after surgical treatment of hidradenitis suppurativa. Br Med J (Clin Res Ed). 1987;294:487-9.

138. Rompel R, Petres J. Long-term results of wide surgical excision in 106 patients with hidradenitis suppurativa. Dermatol Surg. 2000;26:638-43.

139. Nweze N, Parsikia A, Ahuja R, Joshi ART. Axillary Hidradenitis: Risk factors for recurrence after surgical excision in 214 patients. Am Surg. 2018:84:422-7.

140. Deckers IE, Dahi Y, van der Zee HH, Prens EP. Hidradenitis suppurativa treated with wide excision and second intention healing: a meaningful local cure rate after 253 procedures. J Eur Acad Dermatol Venereol. 2018;32:459-62.

141. Kofler L, Schweinzer K, Heister M, Kohler M, Breuninger H, Häfner HM. Surgical treatment of hidradenitis suppurativa: an analysis of postoperative outcome, cosmetic results and quality of life in 255 patients. J Eur Acad Dermatol Venereol 2018;32:1570-4.

142. Shanmugam VK, Mulani S, McNish S, Harris S, Buescher T, Amdur R. Longitudinal observational study of hidradenitis suppurativa: impact of surgical intervention with adjunctive biologic therapy. Int J Dermatol. 2018;57:62-9

143. Hazen PG, Hazen BP. Hidradenitis suppurativa: Successful treatment using carbon dioxide laser excision and marsupialization. Dermatol Surg. 2010;36:208-13.

144. Finley EM, Ratz JL. Treatment of hidradenitis suppurativa with carbon dioxide laser excision and second-intention healing. J Am Acad Dermatol. 1996;34:465-9.

145. Madan V, Hindle E, Hussain W, August PJ. Outcomes of treatment of nine cases of recalcitrant severe hidradenitis suppurativa with carbon dioxide laser. $\mathrm{Br}$ Dermatol. 2008;159:1309-14.

146. Mikkelsen PR, Dufour DN, Zarchi K, Jemec GB. Recurrence rate and patient satisfaction of CO2 laser evapration of lesions in patients with hidradenitis suppurativa: a retrospective study. Dermatol Surg. 2015;41:255-60.

147. Highton L, Chan WY, Khwaja N, Laitung JK. Treatment of hidradenitis suppurativa with intense pulsed light: a prospective study. Plast Reconstr Surg. 2011;128:45965.

148. Saunte DM, Lapins J. Lasers and Intense Pulsed Light hidradenitis supurativa. Dermatol Clin. 2016:34:111-9.

\section{AUTHORS'CONTRIBUTIONS}

Renata Ferreira Magalhães

(iD) ORCID

0000-0001-9170-932X

Approval of the final version of the manuscript; Conception and planning of the study; Elaboration and writing of the manuscript; Obtaining, analyzing and interpreting the data; Effective participation in research orientation; Critical review of the literature; Critical review of the manuscript

Maria Cecília Rivitti-Machado $\quad$ (iD) ORCID 0000-0003-2910-7330

Approval of the final version of the manuscript; Conception and planning of the study; Elaboration and writing of the manuscript; Critical review of the literature; Critical review of the manuscript

Gleison Vieira Duarte $\quad$ (iD) ORCID 0000-0003-4160-5447

Approval of the final version of the manuscript; Elaboration and writing of the manuscript; Obtaining, analyzing and interpreting the data; Critical review of the literature; Critical review of the manuscript

$\begin{array}{lll}\text { Roberto Souto } & \text { (iD) ORCID } 0000-0001-7136-6008\end{array}$

Approval of the final version of the manuscript; Elaboration and writing of the manuscript; Critical review of the literature; Critical review of the manuscript

$\begin{array}{lll}\text { Daniel Holthausen Nunes } & \text { (iD) ORCID } \quad 0000-0002-1303-5419\end{array}$

Approval of the final version of the manuscript; Elaboration and writing of the manuscript; Critical review of the literature; Critical review of the manuscript

$\begin{array}{lll}\text { Mario Chaves } & \text { (iD) ORCID 0000-0003-2943-0322 }\end{array}$

Approval of the final version of the manuscript; Elaboration and writing of the manuscript; Critical review of the literature; Critical review of the manuscript

$\begin{array}{lll}\text { Sérgio Henrique Hirata } & \text { (ID) ORCID } & 0000-0003-4026-9664\end{array}$

Approval of the final version of the manuscript; Elaboration and writing of the manuscript; Critical review of the literature; Critical review of the manuscript

Andrea Machado Coelho Ramos $\quad$ (iD) ORCID 0000-0002-7982-9107

Approval of the final version of the manuscript; Elaboration and writing of the manuscript; Critical review of the literature; Critical review of the manuscript

How to cite this article: Magalhães RF, Rivitti-Machado MC, Duarte GV, Souto R, Nunes DH, Chaves M, Hirata SH, Ramos AMC. Consensus on the treatment of hidradenitis suppurativa - Brazilian Society of Dermatology. An Bras Dermatol. 2019;94(2 Suppl 1):S7-19. 